\title{
The Relation of Attachment to God with Spirituality among
}

\section{Yoga Practitioners}

\author{
Naseem Ahmad $^{1 *}$, Nasheed Imtiaz ${ }^{2}$
}

\section{ABSTRACT}

Context: Attachment to God and Spirituality are the topic for great concern among Yoga practitioners. Hall, Fujikava, Halcrow and Hill (2009) suggested that attachment to God and Implicit spiritual knowledge were related with each other. The present investigation is an effort to study the relation of attachment to God with Spirituality among Yoga practitioners. For this purpose yoga practitioners ( $\mathrm{N}=60)$ with age ranging from 35 to 60 years were selected as sample from the various Yoga Training Centres and Institutions of Delhi NCR. For assessing attachment to God, Attachment to God Inventory (AGI) given by Beck and McDonald was employed and for assessing spirituality, Spirituality Scale (SS) developed by Hadart et al was used. Results of the present study were analysed using Pearson-r correlation. The main finding of the current investigation is that there is no significant correlation any of the dimensions of attachment to God and spirituality except anxious attachment to God (dimension of attachment to God) and belief in God (dimension of spirituality), which are negatively correlated ( $r=.276)$ at 0.05 level. The study has important implications for intervention programs.

Keywords: Attachment to God, Spirituality and Yoga Practitioners.

Attachment theory focuses on the relationships and bonds between people, particularly longterm relationships including those between a parent (usually the mother) and child and between romantic partners. British psychologist John Bowlby was the first attachment theorist, describing attachment as a "lasting psychological connectedness between human beings."

In 1970's research, psychologist Mary Ainsworth expanded greatly upon Bowl by's original work. Based upon the responses of infants, Ainsworth observed three major patterns of attachment: secure attachment, ambivalent-insecure attachment, and avoidant-insecure attachment. Later, researchers Main and Solomon (1986) added a fourth attachment style called disorganized-insecure attachment. A number of studies since that time have supported

\footnotetext{
${ }^{1}$ Research scholar, Department of Psychology, Aligarh Muslim University, Aligarh

${ }^{2}$ Assistant Professor, Department of Psychology, Aligarh Muslim University, Aligarh

*Responding Author

(C) 2016 I N Ahmad, N Imtiaz; licensee IJIP. This is an Open Access Research distributed under the terms of the Creative Commons Attribution License (http://creativecommons.org/licenses/by/2.0), which permits unrestricted use, distribution, and reproduction in any Medium, provided the original work is properly cited.
} 
Ainsworth's patterns of attachment and have indicated that attachment patterns also have an effect on behaviours later in life.

\section{Attachment to God}

Psychoanalysis has a long history of conceptualizing religious belief in terms of relationship between the self and others (Kirkpatrick, 2005). A religious person's faith of relationship with a God might leave open the question of whether such a relationship is an attachment relation. Kirkpatrick and Shaver (1992) recognized parallels between qualities inbuilt in relationships with parents and relationships with God. Within monotheistic religions, God is seen as one who shows and protects his followers, similar to a parent. Thus, paralleling Ainsworth, Blehar, Waters and Wall (1978) theoretical conceptualization of parent-child attachment and Hazan and Shaver's (1987) conceptualization of adult romantic attachment, Kirkpatrick and Shaver (1992) theorized that there are three patterns of attachment to God. They found empirical evidence that people with a secure God attachment have a relationship to God characterized by feelings of safety, comfort, and satisfaction; people with an avoidant God attachment have a detached and aloof relationship to God; and people with an anxious-ambivalent God attachment have a relationship to God characterized by feelings of conflict and confusion. Attachment to God is related to numerous markers of health and well-being. For example, Kirkpatrick and Shaver (1992) found that a secure God attachment style was associated with moreover all gratification and less physical illness than an insecure God attachment style. Those who were insecurely attached to God reported higher levels of anxiety, loneliness, and depression. One way through which God attachment may affect mental and physical health is coping strategy. On the other hand, several studies have provided partial support for some form of compensation. Individuals with histories of avoidant attachment were found to be more likely to have experienced a sudden religious conversion during adolescence or adulthood (Granqvist, 1998; Granqvist \& Hagekull, 1999; Kirkpartrick, 1999; Kirkpatrick \& Shaver, 1990). In a four- year longitudinal study, women who reported insecure adult attachment styles in romantic relationships (both anxious and avoidant) were more likely to have "found a new relationship with God" than women who reported a secure attachment history (Kirkpatrick, 1997). In addition, women with an anxious attachment history were more likely to have had a religious experience or conversion during that time than women with avoidant and secure histories. In a second longitudinal study by Kirkpatrick (1998) using Bartholomew and Horowitz's (1991) four-category self-classification measure of romantic attachment, individuals classified as preoccupied and fearful displayed a greater longitudinal increase in religiosity relative to those reporting positive self-models. Granqvist (2002) replicated this, finding that a significantly higher proportion (16.3\%) of those with an insecure attachment history with mother reported an increase in the importance of their religious beliefs during their adulthood (after age 22) than those reporting a secure attachment history with mother (6.5\%).

Secure attachment in current relationships has been associated with perceptions of God as more loving, less detached and controlling (Brokaw \& Edwards, 1994; Hall, Brokaw, Edwards, \& 
Pike, 1998), and of one's relationship with God as more stable and emotionally close (Hall \& Edwards, 2002). In addition, retrospective reports of secure attachment history have been associated with higher levels of orthodox Christian beliefs (Merck \& Johnson, 1995). Two recent studies found evidence directly supporting correspondence between anxious attachment in romantic relationships and anxious attachment to God (Beck \& McDonald, 2004; Rowatt\& Kirkpatrick, 2002).

\section{Spirituality}

Spirituality is a complex multidimensional concept (Cook 2004; Hill et al. 2000; George et al. 2000; Moberg, 2002). The concept confronts definite boundaries, which also applies to other latent constructs that are often used, such as character, well-being and mental health (Miller and Thoresen, 2003). Many definitions of spirituality have been proposed from various disciplines and perspectives. For example, spirituality has been described as "the way in which individuals realize and live their lives in view of their ultimate meaning and value" (Muldoon and King, 1995), as"search for sacred.” (Snyder, 2007),as “a personal experience of the sacred” (Vaughan, 1991) and as "a quality that goes beyond religious connection, that struggles for inspirations, respect, amazement, meaning and purpose, even in those who do not have faith in any good.” (Murray and Zenter, 1989).. It involves belief and obedience to a supreme power usually called God, who wheels the universe and the destiny of human beings. It involves the ways in which people accomplish what they embrace to be the purpose of their lives, a search for the meaning of life and a sense of connectedness to the universe. The universality of spirituality outspreads through faith and culture. At the same time, spirituality is very much personal and unusual to each individual. It is a divine world of human experience. Spirituality produces in man qualities such as affection, trustworthiness, tolerance, acceptance, and empathy, a sense of detachment, faith, and optimism. Of late, there are some reports which suggest that some areas of the brain, mainly the non-dominant one, are involved in the gratitude and accomplishment of spiritual values and experiences (Verghese, 2005). There is no single, widely-agreed definition of spirituality, (Koenig, 2012). Zinnbauer, Pargament and Scott (1999) described five studies in which various groups of individuals were asked to describe spirituality. They concluded that differences in the responses of the participants exceeded by far the similarities. McSherry and Cash (2004) even specified that we should accept that the word 'spirituality' has different meanings.

Yoga is the science of connecting soul to the super soul (God) and attachment to God shows the relationship between the God and the human beings, (Kumar, 2008). Spirituality may refer to almost any kind of meaningful activity, personal growth or blissful experiences. So, the relationship between spirituality and attachment to God can be best studied among yoga practitioners. 
On the basis of the above literature, following objectives were framed:

- To assess the dimensions of attachment to God (i.e. avoidant attachment to God and anxious attachment to god) and to assess the dimensions of spirituality (i.e. belief in God, search for meaning, mindfulness and feeling of security).

- To explore the relationship between the attachment to God and Spirituality

Based on above mentioned objectives, the hypotheses for the present research were as follows:

- There would be a significant relationship between the dimensions of attachment to God i.e. avoidant attachment to God and anxious attachment to God and the dimensions of spirituality i.e. belief in God, search for meaning, mindfulness and feeling of security.

\section{METHOD}

\section{Sample}

A total of 60 Yoga Practitioners age ranging from 35 to 60 years, contacted for present study. Sample was collected from different centres of Akhil Bhartiya Yoga Sansthan of Delhi and NCR.

\section{Tools}

Attachment to God inventory: (AGI; Beck \& McDonald, 2004) is 28-item scale base don the Experiences in Close Relationships Scale, developed by Brenrian, Clark, and Shaver (1998). It contains 14 items on the Anxiety subscale (Cronbach alpha of. 82 with the current sample), and 14 items on the Avoidance subscale (Cronbach alpha of .83). Examples of the anxiety items are:"I often worry out whether God is pleased with me."And" I fear God does not accept me when I do wrong. "Examples of the avoidance items are:"I prefer not to depend too much on God."And" I just don't feel deepened to be close to God."The AGI demonstrated good factor structure and construct a lidityina multiple sample.

Spirituality Scale: (SS; Hadart et al, 2011) consists of 20 items, 5 items for each dimensioni.e. belief in God, search for meaning, mindfulness and feeling of security. The subscales have good reliability (.78 $\leq$ Cronbachs $\alpha \leq .97)$ and medium positive inter-correlations $(.26 \leq \mathrm{r} \leq .52)$.

\section{Procedure:}

For the purpose of proposed research data was collected from different centers of Akhil Bhartiya Yoga Sansthan of Delhi NCR. After rapport formation all required scales with instructions were administered on all the participants. The participants were informed that the information collected from them will be kept confidential and will be used only for the study of research purposes. The participants were asked to fill the questionnaires of attachment to God and spirituality.

\section{Statistical Analysis:}

Pearson $r$ Product moment correlation has been used to analyse the data for the present study. 


\section{RESULT AND DISCUSSION}

The present study was to find the relationship of attachment to God with spirituality in Yoga Practitioners (age 35-60) Obtained data were analysed by Pearson $r$ Correlation. Results are being presented in the following tables:

Table 1: Summary of inter-correlation of attachment to God and spirituality of Yoga Practitioners $(\mathrm{N}=60)$.

\begin{tabular}{|c|c|c|c|c|c|c|}
\hline & $\begin{array}{l}\text { Avoidant } \\
\text { attachment } \\
\text { to God }\end{array}$ & $\begin{array}{l}\text { Anxious } \\
\text { attachment } \\
\text { to God }\end{array}$ & $\begin{array}{l}\text { Belief in } \\
\text { God }\end{array}$ & $\begin{array}{l}\text { Search } \\
\text { for } \\
\text { meaning }\end{array}$ & Mindfulness & $\begin{array}{l}\text { Feeling of } \\
\text { security }\end{array}$ \\
\hline $\begin{array}{l}\text { Avoidant } \\
\text { attachment } \\
\text { to God }\end{array}$ & & -.147 & -.031 & -.050 & -.076 & -.213 \\
\hline $\begin{array}{l}\text { Anxious } \\
\text { attachment } \\
\text { to God }\end{array}$ & & & $-.276^{*}$ & -.093 & .109 & .023 \\
\hline $\begin{array}{l}\text { Belief in } \\
\text { God }\end{array}$ & & & & .248 & .154 & -.062 \\
\hline $\begin{array}{l}\text { Search for } \\
\text { meaning }\end{array}$ & & & & & .121 & -.008 \\
\hline Mindfulness & & & & & & -.105 \\
\hline $\begin{array}{l}\text { Feeling of } \\
\text { security }\end{array}$ & & & & & & \\
\hline
\end{tabular}

*. Correlation is significant at the 0.05 level (2-tailed)

Table 1 indicated that there is a significant negative correlation between avoidant attachment to God (dimension of attachment to God) and belief in God (dimension of spirituality), ( $r=-.276$ ), which depicted that more the avoidant attachment to God the less would be the belief in God and vice versa.

There is no significant correlation between any other constructs of attachment to God and spirituality.

Thus, the hypothesis which stated that' there would be a significant relationship between the dimensions of attachment to God (i.e. avoidant attachment to God and anxious attachment to God) and the dimensions of spirituality (i.e. belief in God, search for meaning, mindfulness and feeling of security) is partially accepted.

The above finding can be supported from the study by Hall, Fujikawa, Halcrow, Hill and Delaney (2009), who found that the dimensions of attachment to God (i.e. avoidant attachment to God and anxious attachment to God) were negatively correlated with the spirituality. The result 
of the present investigation is also in parallel with the study of Okozi (2010), who found that attachment to God was inversely correlated with belief in God, positive relationship with others, personal growth and purpose in life and Hernandez, Salerno and Bottoms (2010) found a significant positive correlation between attachment to God (secure attachment to God) and spiritual coping in their study. Thus, he concluded that people who are securely attached to God have a good spiritual coping.

\section{CONCLUSION}

Thus, the findings of the present investigation illustrated that avoidant attachment to God (dimension of attachment to God) have a significant negative relationship with belief in God (dimension of spirituality). Furthermore, people with high avoidant attachment style have low belief in God. Even though the present study is not free from limitations, it can be used as the basis for many other future researches. The outcome of the present study can also be implemented in intervention programs, as it has shown a very important role of attachment to God and spirituality among yoga practitioners.

\section{REFERENCES}

Ainsworth, M. D. S., Blehar, M. C., \& Wall, S. (1978). Patterns of Attachment: a psychological study of strange situation. Hillsdale, NJ. Erlbaum.

Bowlby, J (1969). Attachment and loss.Vol.1 Attachment. New York: Basic Books.

Bowlby, J (1973). Attachment and loss.Vol.2Separation.New York: Basic Books.

Bowlby, J (1980). Attachment and loss.Vol.3Loss.New York: Basic Books.

Bartholomew, K. (1990).Avoidance of intimacy: An attachment perspective. Journal of Social and Personal Relationships,7,147-17

Beck, R. \& McDonald, A. (2004). Attachment to God: The Attachment to God Inventory, tests of working model correspondence, and an exploration of faith group differences. Journal of Psychology and Theology,32,92-103.

Brennan, K. A., Clark, C. L., \& Shaver, P R. (1998). Self-report measures of adult romantic attachment. An integrative overview. In J. A. Simpson \&W.S .Rholes (Eds),Attachment theory and close relationships. New York: Guilford Press,46-76.

Cassibba R, Granqvist P, Costantini A. (2013). Mothers' attachment security predicts their children's sense of God's closeness. Attachment and Human development.

Cook CCH. (2004). Addiction and spirituality. Addiction: The Society for the Study of Addiction,99,539-551.

George LK, Larson DB, Koenig HG, McCullough ME. Spirituality and health: What we know, what we need to know. Journal of Social and Clinical Psychology, 19, 102-116.

George LK, Larson DB, Koenig HG, McCullough ME. Spirituality and health: What we know, what we need to know. Journal of Social and Clinical Psychology,19,102-116.

Granqvist,P.,\&Hagekull,B.(2000).Religiosity,adultattachment,andwhy"singles"aremorereligious. The International Journal for the Psychology of Religion,10,111-123. 
Hall T. W., Fujikawa A., Sarah R. Halcrow, and Hill P. C. (2009). Implicit Spirituality: Clarifying Correspondence and Compensation Models. Journal of Psychology and Theology, 37, 227-242.

Hall, T.W., \& Brokaw, B.F (1995). There lationship of spiritual maturity to level of object relations development and God image. Pastoral Psychology,43,373-391.

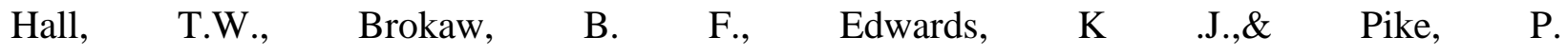
L.(1998).Anempiricalexplorationofpsychoanalysisandreligion:Spiritualmaturityandobject relations development and God image. Journal for the Scientific Study of Religion,37, 30231.

Hardt J., Schultz S., Xander C., Becker G., Dragan M. (2012). The Spirituality Questionnaire: Core Dimensions of Spirituality. Journal of Scientific Research: An Academic Publisher.

Hill PC, Pargament KI, Hood RW, McCullough ME, Swyers JP, Larson DB, et al. Conceptualizing religion and spirituality: Points of commonality, points of departure. Journal for the Theory of Social Behaviour,30,51-77.

Kirkpatrick, L.A.(1997).A longitudinal study of changes in religious belief and behaviour as function of individual differences in adult attachment style. Journal for the Scientific Study of Religion,36,207-217.

Kirkpatrick, L. A. (1998). God a as substitute e attachment figure: A longitudinal study of adult attachment style and religious change in college students. Personality and Social Psychology Bulletin, 24,961-973.

Kirkpatrick, L.A.(1999).Attachment and religious representations and behaviour. In Handbook of attachment: Theory, research, and clinical applications.803-822.NewYork: Guilford Press.

Kirkpatrick,L. A. \&Shaver, P. R.(1990). Attachment the ory and religion: Childhood attachments, religious beliefs, and con version. Journal for the Scientific Study of Religion, 29,315-334.

Koenig, H. G. (2008) Research on religion, spirituality, and mental health: A review. Canadian Journal of Psychiatry.

Kumar, R. (2008). How to be one with God: An autobiography of a scientist yogi. Sterling Publishers Pvt. Ltd.

McSherry W, Cash K. (2004). The language of spirituality: an emerging taxonomy. International Journal of Nursing Studies, 41, 151-161.

Miller G, Fleming W, Brown-Anderson F. (1998). Spiritual well-being scale ethnic differences between Caucasians and African-Americans. Journal of Psychology and Theology, 26, 358-364.

Miller WR, Thoresen CE (2003). Spirituality, religion, and health—an emerging research field. American Psychologist, 58,24-35.

Moberg DO (2002). Assessing and measuring spirituality: Confronting dilemmas of universal and particular evaluative criteria. Journal of Adult Development, 9:47-60.

Muldoon M, King N. (1995).Spirituality, health care, and bioethics. Journal of Religion and Health.Winter,34 (4), 329-49. 
Murray RB, Zenter JB (1989). Nursing concepts for health promotion. London: Prentice-Hall.

Okozi I. F. (2010).Attachment to God: Its Impact on the Psychological Wellbeing of Persons with Religious Vocation. Seton Hall University Dissertations and Theses (ETDs). Paper 302.

Rowatt WC, Kirkpatrick LA (2002). Dimensions of attachment to God and their subsequent attachment to affect, religiosity, and personality constructs. Journal for the Scientific Study of Religion, 41,637-651.

Salernoand J. M. and Bottoms B. L. (2010).The International Journal for the Psychology of Religion,20, 97-108.

Snyder C.R. (2007). Positive Psychology: The Scientific and Practical Explorations of Human Strengths. Sage publication.

Vaughan F. (1991).Spiritual issues in psychotherapy. Journal of Transpersonal Psychology, 23,105-119.

Verghese A. (2008). Spirituality and Mental health. Indian Journal of Psychiatry.

Zinnbauer BJ, Pargament KI, Scott AB (1999). The emerging meanings of religiousness and spirituality: Problems and prospects. Journal of Personality, 67,889-919 